\title{
Los misterios urbanos en el mundo: circulación, transferencias, apropiaciones ${ }^{*}$
}

\section{Urban Mysteries in the World: Circulation, Transfers, Appropriations}

\author{
Marie-Eve Thérenty \\ Université Paul Valéry, Montpellier 3, Francia \\ marie-eve.therenty@univ-montp3.fr
}

Resumen: En este estudio se aborda un ejemplo de la primera globalización de la cultura a partir de Los misterios de París, de Eugène Sue -publicados originalmente por entregas en el Journal des Débats, entre junio de 1842 y octubre de 1843-, que representa el inicio de los llamados misterios urbanos. La novela Los misterios de París, cuestiona aspectos relacionados con la modernidad de la ciudad, al mostrar, entre otros aspectos, el crimen, el tejido social, lo misterioso. El misterio urbano se reprodujo en distintos países, lo que habla de la circulación y apropiación de la novela de Sue. De ahí que se plantee la necesidad de estudiar los soportes con un enfoque transnacional de las literaturas. Con base en los resultados de las indagaciones emprendidas por el proyecto de investigación colectivo, interinstitucional e internacional Médias 19, es posible proponer algunas hipótesis sobre las leyes que rigen en la república mundial de las letras, como son: La ley de la transferencia: no hay transferencia sin mutación; Instantaneidad y desfase; La ley de la hibridación.

Palabras clave: Misterios urbanos; Sue; novela; circulación; transferencias; apropiaciones; siglo XIX.

* El texto se escribió originalmente en francés. Traducción de Kenya Bello. 
Abstract: This study explores an example of the first globalization of culture through Eugène Sue's Les Mystères de Paris, originally published in installments in the Journal des Débats, between June 1842 and October 1843, which represents the beginning of the urban mysteries. The novel The Mysteries of Paris questions aspects of the city's modernity by showing, among other things, its crime, social fabric and mysterious aspects. The urban mystery was reproduced in different countries, which speaks of the circulation and appropriation of Sue's novel, hence the need to study the bases with a transnational approach to literature. On the basis of the results of the research undertaken by the collective, inter-institutional and international research project, Médias 19, it is possible to propose some hypotheses about the laws in the republican world of letters, such as: The Law of Transference: there is no transference without mutation; instantaneity and misalignment; and The Law of Hybridization.

Key words: Urban mysteries; Sue; novel; circulation; transfers; appropriations; 19th century.

Fecha de recepción: 16 de agosto de 2016 Fecha de aceptación: 1 de septiembre de 2016

$E_{f}^{n}$ n su artículo "Filología de la lectura mundial", Eric Auerbach evoca la dificultad que implica sintetizar de forma abarcadora la literatura mundial, así como la necesidad de encontrar un ansatzpunkt un punto de irradiación. "Ese punto de partida es un conjunto de fenómenos circunscritos claramente, fáciles de asir, y su interpretación debe poseer tal irradiación que permita ordenar e interpretar, por extensión, un ámbito mucho más vasto que el de partida" (Auerbach, 2005). Así, un ansatzpunkt bastante útil para asir la mundialización literaria es el desarrollo global de la nebulosa de los misterios urbanos. Es posible ofrecer una muestra de esta primera globalización de la cultura a través del análisis del texto que describe una metrópolis del siglo xix:

Estos son los misterios aterradores del barrio repugnante que se encuentra en pleno corazón de esta metrópolis inmensa. De John Street a Saffron Hill, de West Street a Clerkenwell Green, hay un laberinto de pasajes estrechos, asfi-

\section{()(1) $(9$}


xiados por la suciedad, por los olores pestilentes y nauseabundos; poblados por gente que nació, que vive y muere en medio de la miseria, la carencia, la pobreza y el crimen (Reynolds, 1845).

Estos barrios extensos sólo tienen calles estrechas, formadas por casas de tablones, cuyas estructuras están toscamente rellenadas con yeso. Su aspecto es lúgubre y siniestro. Las ventanas están atravesadas por cuerdas: lo que se ve son harapos extendidos, que al haber sido lavados en un agua impura tienen manchas más extensas de las que les querían quitar. En la planta baja se encuentra casi siempre una habitación que sirve de tienda, se entra por un portalón; el piso, sin adoquines, es desigual y está lleno de hoyos, donde se aloja la basura (Féré, 1981).

La puerta no tardó en abrirse y las visitantes vieron aparecer a una vieja sucia y fea, obesa, con la carne colgada, casi en andrajos. Tenía una cara gruesa, fofa y completamente roja, parecía que sudaba sangre; y mechas horribles de pelos grises salían debajo de su gorro de paño, que tenía el color del lodo, de donde debió haber sido recogido. ${ }^{1}$

\section{¿QUÉ METRÓPOLIS SE DESCRIBEN AQUÍ? ¿QUIÉN ES EL AUTOR?}

De hecho, se trata de tres ciudades diferentes: Londres, Ruán y San Petersburgo, y de tres novelas diferentes: Los misterios de Londres, de Reynolds, Los misterios de Ruán, de Octave Féré, y Los bajos fondos de Petersburgo, de Krestovski, que son prueba de la circulación mundial de los "misterios urbanos" en el siglo xIX.

En efecto, inspirados por Los misterios de París, de Eugène Sue -que se publicaron por entregas en el Journal des Débats, entre junio de 1842 y octubre de 1843-, los misterios urbanos constituyen una nebulosa novelesca que

${ }^{1}$ Ivan Doff. Les Mystères de Saint-Petersbourg. Le petit roman-feuilleton, 26 de mayo de 1878. Es una traducción de Los bajos fondos de Petersburgo, de V. V. Krestovski, cuyo original apareció entre 1864-1867 en la revista Otetchestvennye zapiski.

\section{()(1) $(3$}


se desarrolló principalmente en Europa, en América del Norte, en América Latina, así como en la commonwealth, antes de desarrollarse en Asia (China y Japón) al cambio de siglo.

¿Por qué razón Los misterios de París constituyeron una matriz tan fecunda para la literatura mundial? Se trata de un texto que de hecho es excepcional, pero sin duda no lo es tanto por su belleza intrínseca, como por su convergencia con la época y su labilidad. De entrada, la novela cuestiona una serie de rasgos relacionados con la modernidad: la ciudad, el crimen, la descripción del tejido social, la promesa de revelar lo que está oculto, subterráneo, y una reflexión sobre las identidades sociales poco estables después de la sacudida revolucionaria. Pero sobre todo, Los misterios de París, conjugan múltiples principios antinómicos, que les dan una forma plástica propicia para una resignificación inmediata. En la novela se escenifica toda una serie de tensiones y se enlistan ciertos paradigmas: internacional/nacional/local; urbano/rural, los bajos fondos/la elite... Eugène Sue, que antes había sido un escritor marítimo -la investigadora estadunidense Margaret Cohen mostró que la novela marítima era junto con la novela histórica, en la que Sue ya se había ejercitado, una de las primeras formas mundialmente conectadas-, creó de golpe una forma-mundo.

Es a nivel de su poética donde la novela encierra indudablemente uno de los secretos de su fecundidad y su emulación. A caballo entre el periodismo y la ficción, entre sensacionalismo y realismo, Los misterios de París se estructuran a partir de una hibridación estrecha entre romance y novel, para retomar una categoría de la ficción anglosajona. Del lado del romance, una ficción hirsuta, sensacionalista y llena de peripecias, de niños extraviados y encontrados, de venganzas hiperbólicas, de efectos suspensivos, de motivos góticos. Del lado de la novel, una voluntad de describir lo real, de abarcar a todas las clases sociales de forma panorámica, de proporcionar estadísticas, de denunciar las injusticias de la sociedad de la época, de hacer periodismo de actualidad. De ahí que las adaptaciones pudieran elegir, e incluso superar, el aspecto sensacionalista de la ficción (como The mysteries of London) o, por el contrario, trabajar la fisonomía de la sociedad (como I misteri di Napoli).

Por último, si Los misterios de París tuvieron tanto éxito, se debió a que la novela había salido del periódico y a que acompañó su entrada en la era mediática. No olvidemos que la novela nació en el folletín y que la tensión romance-novel reproduce la oposición entre lo que llamo la "planta alta infor-

\section{()(1) $(9$}


mativa" y la "planta baja de la ficción". En el contexto de la mundialización, queda claro que la prensa del siglo xIx constituyó un espacio intersticial de transición, de intersección y de hibridación bastante permeable. El misterio urbano, a menudo obra de escritores-periodistas, se cultivó de manera ejemplar en las zonas cuyos medios de comunicación estaban más desarrollados (en Inglaterra o en Estados Unidos), mientras que en otros países contribuyó al desarrollo de la prensa, como en México, donde la traducción de Los misterios de París, en 1845, inauguró el folletín en El Siglo XIX. De tal suerte, esta novela plantea la necesidad de estudiar los soportes con un enfoque transnacional de las literaturas.

Los misterios de París se difundieron internacionalmente según tres modelos que muchas veces se traslaparon, en lugar de sucederse. La novela circuló con el aspecto del Journal des Débats, de las ediciones Gosselin y de los ejemplares ilegales que se fabricaron rápidamente en el norte de Europa. Pero las traducciones, segunda forma de difusión de la novela y condición sine qua non para una dinámica masiva que elimine los compartimentos de la literatura nacional, ${ }^{2}$ llegaron a publicarse incluso antes de que terminaran las entregas de la novela. A lo largo del siglo xix hubo al menos 20 traducciones al inglés (de las cuales diez se hicieron en Inglaterra y nueve en Estados Unidos), se cuentan doce traducciones al español, doce al italiano, siete al alemán, seis al portugués, tres al catalán, cuatro al danés ${ }^{3}$... Por último, y ahí reside la particularidad de la novela de Sue frente a otras novelas de folletín urbanas que también tuvieron éxito, como Los mohicanos de París, de Alejandro Dumas (1854), vivió un fenómeno de adaptación en forma de novelas autóctonas, ya fuera retomando el título original, o transformándolo y creando una nueva intriga en los bajos fondos urbanos locales. También en este caso, comparando distintas fuentes, es posible identificar, además de las 74 novelas francesas, 27 misterios italianos, 24 misterios estadounidenses, trece misterios españoles, doce misterios portugueses, y cinco misterios de Montreal, que utilizaron en su título el sintagma Misterios de y añadieron el nombre de algu-

${ }^{2}$ Casanova (2008) mostró que el mundo estaba organizado de acuerdo con una geografía policéntrica, que giraba alrededor de las grandes capitales europeas y principalmente alrededor del "meridiano de Greenwich" (París).

${ }^{3}$ Estos datos provienen de listados de Montpellier, contrastados con las tablas de Schapochnik (2010). Para más detalles sobre la llegada de Los misterios de París a Brasil, véase Meyer (1996).

\section{(ㄷ)(1) $(3$}


na localidad urbana... Algunas de esas novelas, como The mysteries of London, de Reynolds, también tuvieron un alcance internacional, al apropiarse y extender los circuitos de traducción y de difusión clásicos. En consecuencia, se trató de una serie de intercambios y de cruces a escala mundial.

Un equipo internacional, entre Montpellier, París, Nueva York, São Paulo, Lisboa, Montreal y México, se propuso estudiar este fenómeno. Nuestro proyecto "Discursos urbanos, París-México, siglo xix" no era, o no solamente, estudiar estadísticamente, a la manera de los historiadores del libro, la difusión, la traducción y las adaptaciones de la novela de Sue. ${ }^{4}$ Nuestro proyecto tampoco era comparativo, ni buscaba imponer un mismo ritmo, a menos que quisiera enfrentar dificultades aporéticas, a las historias literarias nacionales o hacer coincidir movimientos y cronologías que, como se verá, no estuvieron en absoluto sincronizadas. De manera más ambiciosa, nuestro proyecto aspira a ser una historia transnacional, queremos estudiar la manera en que algunos textos circularon, así como el modo en que se los reapropiaron y los utilizaron a nivel local. Sin embargo, en ese marco de investigación, el dispositivo del distant reading, propuesto por el estadunidense Franco Moretti, no resultaba adecuado. La revisión de catálogos y la lectura de las historias literarias eran un punto de partida necesario, pero insuficiente, pues la mayor parte de los textos que deseamos estudiar pertenece al grupo que Margaret Cohen llama great unread. Si Los misterios de Londres, de Reynolds, Los misterios de Lisboa, de Camilo Castelo Branco, o Los bandidos

${ }^{4}$ Instituciones participantes en el proyecto: Université de Montpellier 3, Paul Valéry e Instituto Mora.

Para el coloquio: Université Paul Valéry, Montpellier 3-Instituto de Investigaciones Dr. José María Luis Mora-Dirección de Estudios Históricos-Instituto Nacional de Antropología e Historia-Instituto Tecnológico de Monterrey, Campus Santa Fe. Participantes por Francia: Alain Vaillant (Université Paris) OuestMarie-Eve Thérenty (Université Montpellier 3, Paul Valéry); Dominique Kalifa (Université Paris 1, Panthéon Sorbonne); Corinne Saminadayar-Perrin (Université de Montpellier 3, Paul Valéry); Joan Verillac (Université de Nîmes); Helle Waalhberg. Por México: José Joaquín Blanco (Dirección de Estudios Históricos-INAH); Lillian Briseño Senosiain (ITESM, campus Santa Fe); Emiliano Canto Mayén (estudiante de doctorado en Historia, El Colegio de México, A. C.); Miguel Ángel Castro (Instituto de Investigaciones Bibliográficas-UnAM); María Esther Pérez Salas C. (Instituto de Investigaciones Dr. José María Mora); Javier Rodríguez Piña (Universidad Autónoma Metropolitana, Azcapotzalco); Antonio Saborit (Dirección de Estudios Históricos-INAH, actualmente director del Museo Nacional de Antropología); Laura Suárez de la Torre (Instituto de Investigaciones Dr. José María Luis Mora).

\section{()(1) $\$$}


de Río Frío, de Payno, ocupan un lugar importante en las historias literarias nacionales, no existían estudios sobre Los misterios de Pargovoulo, novela publicada en 1845 en la revista rusa L'Tllustration, de Nestor Kukolnik, ni sobre Los misterios de Chamberí, pequeña novela satírica publicada en el periódico español El Laberinto (antes el distrito de Chamberí fue un pueblo rodeado de campos y de huertos a las afueras de Madrid). Por eso era necesario que especialistas de la historia nacional de cada país realizaran investigaciones minuciosas, como la que hizo Vicente Quirarte sobre esta literatura urbana en México (Quirarte, 2001).

Este programa de investigación, aunque analiza el siglo XIX, se integra plenamente en la cultura global. Sus intuiciones, sus condiciones de realización y sus resultados dependieron de la nueva cultura universitaria, definitivamente mundializada. Requirió varios equipos de historiadores de las literaturas nacionales, sensibles a los intercambios internacionales, lo que sin duda evitó, en parte, la tentación del etnocentrismo. Si bien la síntesis se volvió más difícil. Se desarrolló mediante intercambios en la red y coloquios organizados en todos los rincones del planeta. Iniciaron en México, pues Laura Suárez de la Torre y sus colegas (Antonio Saborit y Lillian Briseño) fueron los primeros que percibieron el interés de estas perspectivas; del 2 al 4 de diciembre de 2011 se organizó el coloquio Discursos urbanos París-México, siglo XIX, ${ }^{5}$ en el que se estudió la riqueza de la matriz de los misterios urbanos de Francia a México. En Montreal, Micheline Cambron realizó, en 2012, un coloquio que se llamó Mystères Urbains France/Québec, centrado principalmente en la cuestión de los misterios de Montreal. ${ }^{6}$ En Francia se organizó un congreso internacional, del 14 al 16 de noviembre de 2013, entre la Universidad de Montpellier y la Sorbona para medir la circulación, la transferencia y las apropiaciones de los misterios de París. Un extenso volumen se publicó, en varias lenguas, dentro del sitio Médias19. Naturalmente, varios colegas mexicanos participaron de esa iniciativa. Del 26 de febrero al 1 de marzo de 2014, Catherine Nesci, de la Universidad de California en Santa Bárbara, organizó el coloquio American Mysteries: Urban Crime Fiction from Eugène Sue's Mysteries of Paris to the American Noir and Steampunk, que trazó la

${ }^{5}$ Las actas de dicho coloquio acaban de publicarse en Suárez de la Torre (2015a).

${ }^{6}$ Las actas se encuentran en http://www.medias19.org/ en la sección Publicaciones, con el título "Los misterios urbanos a la luz de la identidad nacional".

\section{(1)(1) $\$$}


filiación entre los misterios urbanos de Estados Unidos y la novela negra. En diciembre de 2014, Isabel Gil llevó a cabo un coloquio en la Universidad Católica de Portugal: Mysteries of Lisbon. The Global and Intermedial Circulation of Urban Mysteries in Lusophone Literature and Culture (19th-21st Centuries), cuyo objetivo era detenerse en la obra maestra de Camilo Castelo Branco, Misterios de Lisboa, así como en la adaptación realizada por Raoul Ruiz. Nuestro programa también necesitó la creación de algunas herramientas digitales, que empezaron a funcionar a manera de prototipos y con recursos humanos limitados, en la plataforma Médias19. Este primer intento se ampliará con un nuevo programa, llamado Numapresse, cuyo lanzamiento será en 2017 y que pretende aprovechar mejor los algoritmos para medir las circulaciones y su difusión viral en el mundo.

\section{LAS LEYES MISTERIOSAS DE LA MUNDIALIZACIÓN}

De este modo, es posible proponer algunas hipótesis sobre las leyes que rigen en la república mundial de las letras. No era posible enunciarlas sin antes haber leído cientos de textos publicados en continentes distintos, en lenguas diversas. Estas proposiciones son producto de la observación, a veces sorpresiva, a veces desesperada y en otras regocijante, de novelas que en una primera lectura podían parecer más distintas que emparentadas. A continuación, enuncio brevemente tres leyes.

\section{La ley de la transferencia: no hay transferencia sin mutación}

La primera observación que puede hacerse es que la transferencia de un objeto cultural no existe sin mutación. Incluso si el objeto se transfiriera "al vacío", si se nos permite la osadía, es decir, en condiciones perfectas de mantenimiento de sus propiedades intrínsecas -que es pedir lo imposible-, sus condiciones de recepción serían suficientes para transformarlo. A fortiori, cuando la traducción entra en juego. El estudio de la traducción es desde hace tiempo una de las cuestiones clave para la historia transnacional de la literatura, que debe revisarse sistemáticamente tanto en su dimensión cuantitativa (¿qué se traduce?), como en su dimensión cualitativa (¿cómo se

\section{()(1) $\$$}


traduce?). Desde esta perspectiva, los misterios urbanos constituyen un taller emblemático (Armbruster, 2014). Es necesario considerar a cada país de recepción como un sistema global, que incluye las tasas de alfabetización, el público previsible de la obra, al igual que el estado del sistema editorial y mediático. La comparación entre la traducción mexicana y la traducción inglesa fue motivo de sorpresas. Laura Suárez de la Torre (2015b) explica que los editores mexicanos de Los misterios de París practicaron una forma de censura que sacrificó ciertos pasajes considerados inadecuados. María Esther Pérez Salas (2015) también estudió la manera en que los editores mexicanos excluyeron las ilustraciones que representaban los bajos fondos parisinos. De modo que algunos lectores mexicanos pudieron ver en la novela no sólo una especie de manual de civilización francesa, sino una obra de moral. Así, un prologuista mexicano de Los misterios de París escribió: "no hay una sola alma que no venere más que antes la virtud y que no odie más los crímenes y el vicio, tan pronto termina de leer esos cuadros tan vívidos y tan bien esbozados". Es necesario puntualizar que este tipo de traducciones edulcoradas y esta lectura moralizante también se produjeron en otros países. En contraste, la traducción de Dugdale, en Inglaterra, fue una edición ilustrada con 16 xilografías, con un papel mediocre y un formato pequeño, destinada a un público modesto, esencialmente obrero. Este editor, conocido por sus libros obscenos, gravitaba en los círculos radicales. El proyecto de la traducción de Dugdale tuvo por objeto reafirmar el carácter audaz y sensacional de la novela, con el fin de producir un texto lo más divertido posible. Todas las alusiones de la novela a la sexualidad o a la prostitución se destacaron hasta la obscenidad. Dichas traducciones fueron el origen de la confusión, estudiada por Brian Chevasco (2003), sobre la recepción de Eugène Sue en Inglaterra, quien fue despreciado por la elite británica y considerado casi un pornógrafo. Queda claro que los lectores extranjeros de Los misterios de París no tuvieron una única experiencia de lectura de la novela.

\section{Instantaneidad $y$ desfase}

En un principio podría pensarse que desde el siglo xIX se produjo la instantaneidad digital, considerando la diseminación de los misterios urbanos. Las traducciones proliferaron a partir de 1844 en muchos países del mundo. Así,

\section{(1)(1) $\$$}


la novela se publicó por entregas desde 1842 en el periódico danés Dagen. Emiliano Canto Mayén (2015) demostró que una traducción de Los misterios de París llegó a Mérida desde julio de 1845. Las adaptaciones se publicaron casi al mismo tiempo. Una primera revisión del corpus parece mostrar que no está sujeto a la ley del anacronismo, planteada por la investigadora Pascale Casanova en su obra La République mondiale des lettres. De hecho, es necesario distinguir los países con un desarrollo sólido de los medios de comunicación, como Estados Unidos e Inglaterra, donde la hegemonía francesa se cuestionó seriamente y se desarrollaron de manera exitosa e instantánea series que compitieron con las francesas. Mientras que en los países de la periferia, los primeros misterios que se publicaron fueron, o muy miméticos y derivados, o casi siempre satíricos. Es significativo que los grandes misterios urbanos de la periferia, novelas que dejaron huella en las literaturas nacionales, estuvieran claramente desfasados entre sí. "El tiempo convertido en espacio", de acuerdo con los análisis de Pascale Casanova, es el que permite establecer cierta relación con el meridiano de Greenwich. Los misterios de Lisboa, de Camilo Castelo Branco, se publicaron en 1854; Los bajos fondos de Petersburgo, libro sobre los saciados y los hambrientos, de Vsevolod Krestovski, en 1864-1866; I misteri di Napoli, de Francesco Mastriani, en 1869-1870, y agregaría a esta lista la novela impresionante y tardía de Payno, Los bandidos de Río Frío (18891891), después de haber leído los análisis de José Joaquín Blanco (2015) y de Miguel Ángel Castro (2015).

\section{La ley de la hibridación}

Cada una de las obras parece obedecer, en estricto sentido, a un principio dialógico con el género que revisita; dialógico porque los autores se inscriben en una lógica de asimilación contrastiva de ciertos rasgos de un género que perciben como extranjero. Desde el momento en que se trata de describir una cultura nacional que busca afirmar su particularidad respecto a los modelos importados, las obras se reapropian el género mediante una lógica del distanciamiento, para proponer un discurso específico. Los misterios urbanos son también los misterios de una cultura que necesita inventar su originalidad, reafirmándola frente a las literaturas importadas. Fue lo que hizo Luis de la Rosa, como mostró Laura Suárez de la Torre (2015b), cuando publicó en

\section{()(1) $\$$}


el Ateneo, en 1844, su famoso artículo sobre "la utilidad de una literatura en México", en oposición a Los misterios de París.

Desde luego, casi todos esos misterios juegan con las cuestiones de la urbanización, del crimen o de la pobreza, en investigaciones que se realizan en los bajos fondos, tanto de las grandes capitales como de las ciudades pequeñas. Desde luego, todos utilizan un arsenal de procedimientos tópicos directamente importados de la novela gótica, pero reelaborados, actualizados a la luz de la modernidad: niño extraviado y encontrado, desheredados, tatuaje, manuscrito perdido... motivos que en su totalidad remiten a la cuestión central que plantean los misterios: las identidades en la modernidad. Pero las diferencias entre los misterios también son evidentes por varias razones: en principio por el ecosistema en que se concibe la novela (anclaje histórico, evolución social y económica del país, tasas de alfabetización, régimen político, desarrollo del sistema editorial y mediático), y en segunda instancia por el color local que le imprimen los procesos de descripción de las identidades sociales, raciales, sexuadas, esenciales al género; porque a nivel estético e ideológico, la matriz se transforma, mezclándose con las series culturales y literarias nacionales. Por ejemplo, en México con los "relatos tradicionales"; por último, porque el misterio urbano -que en su origen constituye un mestizaje entre la escritura periodística y la ficción, entre novel y romance-tiende a valorizar más o menos, de acuerdo con las culturas y el estatus del escritor, ya sea uno u otro de estos dos polos.

En términos globales, el estudio de los misterios urbanos confirma la hegemonía de la capital de las letras (París lo impulsa todo), al tiempo que el sistema se vuelve más complejo al menos en cuatro niveles:

1. Primero porque el objeto que llega no es el mismo que se va. El sistema de recepción sociológico y editorial influye claramente sobre el contenido y la forma de los objetos impresos.

2. En segundo lugar, porque los equilibrios locales se negocian casi siempre en la negación o en la deconstrucción de la lógica hegemónica y los objetos producidos a partir de la matriz, directamente provenientes de ella, algunas veces se construyen en contraposición a ella. Son ejemplo de esto las numerosas naciones o regiones no urbanizadas donde la moda de los misterios también se desarrolló siguiendo un paradigma que por fuerza debía ser bastante distinto del paradigma francés. La clave era reconstruir otras supremacías, otras jerarquías, deconstruir las poéticas para adaptarlas a problemá-

\section{()(1) $(9$}


ticas puramente nacionales. Así, en México, está claro que el pasado prehispánico y colonial son preponderantes para comprender los misterios mexicanos.

3. Por último, el desarrollo de los sistemas mediáticos inglés y estadunidense les permitió contrapesar la hegemonía francesa y proponer series rivales que también circularon en el espacio mundial.

4. Este último punto remite a la cuestión de los soportes. La circulación del libro y de lo impreso, junto con el auge de la traducción, se han considerado regularmente como factores que permiten y extienden los intercambios literarios, pero la mundialización de los intercambios modificó su dimensión con la llegada de la era mediática. Sin duda este factor no había sido tomado en cuenta hasta ahora. La naturaleza esencialmente mediática de la literatura moderna obliga a considerar que las actividades de comunicación literaria son siempre, a determinada escala, efectos "locales" de la configuración del sistema mediático y que esto ocurre desde el siglo XVIII. Como escribe Guillaume Pinson, una historia transnacional de las literaturas forzosamente debe considerarse a la luz de lo mediático.

\section{LISTA DE REFERENCIAS}

Armbruster, C. (2014). Translating the Mysteries of Paris for the American Market: The Harpers vs The New World. Revue Française d’Études Américaines, 38, 25-39.

Auerbach, E. (2005). En C. Pradeau y T. Samoyault, Où est la littérature mondiale? Francia: PUV.

Blanco, J. J. (2015). Aspectos de la novela popular mexicana en el siglo XIX. En L. Suárez de la Torre (coord.), Tras las huellas de Eugenio Sue. Lectura, circulación y apropiación de Los Misterios de París. Siglo XIX. México: Instituto Mora.

Canto Mayén, E. (2015). Eugène Sue y sus misterios: huellas errantes en las lecturas y literatura yucatecas (1840-1867). En L. Suárez de la Torre (coord.), Tras las huellas de Eugenio Sue. Lectura, circulación y apropiación de Los Misterios de París. Siglo XIX. México: Instituto Mora.

Casanova, P. (2008). La République mondiale des lettres. París: Seuil.

Castro, M. Á. (2015). En busca del niño perdido en las patas sucias y velludas de la ciudad. En L. Suárez de la Torre (coord.), Tras las huellas de Eugenio Sue. Lectura, circulación y apropiación de Los Misterios de París. Siglo XIX. México: Instituto Mora.

\section{()(1) $\$$}


Chevasco, B. P. (2003). Mysterymania: The Reception of Eugene Sue in Britain 1838-1860. Berna: Peter Lang.

Féré, O. (1981). Les mystères de Rouen [1845]. Ruán: Éditions PTC.

Meyer, M. (1996). Folhetim: uma historia. São Paulo: Companhia das Letras.

Pérez Salas, M. E. (2015). Las imágenes de Los Misterios de París en las ediciones mexicanas. En L. Suárez de la Torre (coord.), Tras las huellas de Eugenio Sue. Lectura, circulación y apropiación de Los Misterios de París. Siglo XIX. México: Instituto Mora.

Quirarte, V. (2001). Elogio de la calle: biografía literaria de la ciudad de México, 1850-1992. México: Ediciones Cal y Arena.

Reynolds, G. W. M. (1845). The mysteries of London. Londres: Vickers.

Schapochnik, N. (2010). Edicão, recepcão e mobilidade do romance Les Mystères de Paris no Brasil oitocentista. Varia Historia, 26(44), 591-617, DoI: http://dx.doi. org/10.1590/S0104-87752010000200013.

Suárez de la Torre, L. (coord.) (2015a). Tras las huellas de Eugenio Sue. Lectura, circulación y apropiación de Los Misterios de París. México: Instituto Mora (Historia Social y Cultural).

Suárez de la Torre, L. (2015b). Lecturas y lectores de Misterios en la ciudad de México, siglo xix. En L. Suárez de la Torre (coord.), Tras las huellas de Eugenio Sue. Lectura, circulación y apropiación de Los Misterios de París. Siglo XIX. México: Instituto Mora. 